\title{
Beta-amyloid deposition and Alzheimer's type changes induced by Borrelia spirochetes
}

\author{
Judith Miklossy a,b,*, Andras Kis ${ }^{\mathrm{c}}$, Alexandra Radenovic ${ }^{\mathrm{c}}$, Lisa Miller $^{\mathrm{d}}$, Laszlo Forro ${ }^{\mathrm{c}}$, \\ Ralph Martins ${ }^{\mathrm{e}}$, Krzysztof Reiss ${ }^{\mathrm{f}}$, Nune Darbinian ${ }^{\mathrm{f}}$, Pushpa Darekar ${ }^{\mathrm{b}}$, \\ Laszlo Mihaly ${ }^{\mathrm{g}}$, Kamel Khalili ${ }^{\mathrm{f}}$ \\ a Kinsmen Laboratory of Neurological Research, University of British Columbia, 2255 Wesbrook Mall, Vancouver, BC, Canada V6T 1Z3 \\ ${ }^{\mathrm{b}}$ University Institute of Pathology, Division of Neuropathology, University Medical School (CHUV), 1011 Lausanne, Switzerland \\ ${ }^{\mathrm{c}}$ Department of Physics, Swiss Federal Institute of Technology, CH-1015 Lausanne, Switzerland \\ d National Synchrotron Light Source, Brookhaven National Laboratory, Upton, NY 11973-5000, USA \\ e Sir James McCusker Alzheimer's Disease Research Unit, School of Psychiatry and Clinical Neurosciences, University of Western Australia, \\ Hollywood Private Hospital, Perth, WA, Australia \\ ${ }^{\mathrm{f}}$ Center for Neurovirology and Cancer Biology, College of Science and Technology, Temple University, \\ 1900 North 12th Street, Philadelphia, PA 19122, USA \\ ${ }^{\mathrm{g}}$ Stony Brook University, Department of Physics and Astronomy, Stony Brook, NY 11794-3800, USA
}

Received 19 July 2004; received in revised form 4 January 2005; accepted 26 January 2005

\begin{abstract}
The pathological hallmarks of Alzheimer's disease (AD) consist of $\beta$-amyloid plaques and neurofibrillary tangles in affected brain areas. The processes, which drive this host reaction are unknown. To determine whether an analogous host reaction to that occurring in AD could be induced by infectious agents, we exposed mammalian glial and neuronal cells in vitro to Borrelia burgdorferi spirochetes and to the inflammatory bacterial lipopolysaccharide (LPS). Morphological changes analogous to the amyloid deposits of AD brain were observed following 2-8 weeks of exposure to the spirochetes. Increased levels of $\beta$-amyloid presursor protein (A $\beta P P$ ) and hyperphosphorylated tau were also detected by Western blots of extracts of cultured cells that had been treated with spirochetes or LPS. These observations indicate that, by exposure to bacteria or to their toxic products, host responses similar in nature to those observed in AD may be induced.
\end{abstract}

(C) 2005 Elsevier Inc. All rights reserved.

Keywords: Alzheimer's disease; Hyperphosphorylated tau; Neurofibrillary tangles; Amyloid precursor protein; Granulovacuolar degeneration

\section{Introduction}

It has been known for almost a century that chronic bacterial infection may lead to amyloid deposition in infected tissues and also that amyloidosis can be induced by bacteria under experimental conditions [30]. Alzheimer's disease $(\mathrm{AD})$ is a form of amyloidosis. The amyloid substance that accumulates in the brain is a $4 \mathrm{kDa}$ peptide $(\mathrm{A} \beta)$, which is derived by proteolytic cleavage of amyloid beta precursor protein $(\mathrm{A} \beta \mathrm{PP})[16]$. The pathological mechanism driving

\footnotetext{
* Corresponding author. Tel.: +1 604822 7564; fax: +1 6048227086.

E-mail address: judmik@telus.net (J. Miklossy).
}

the accumulation of this type of amyloid in AD brain remains unclear. Intriguingly, the clinical and pathological hallmarks of $\mathrm{AD}$ are present in dementia paralytica in the tertiary stage of syphilis caused by the spirochete Treponema pallidum $[2,3,27]$. Recent observations have shown that several bacteria contain amyloidogenic proteins, including spirochetes $[5,15,19,22,23,26]$. The outer surface protein (OspA) of Borrelia burgdorferi spirochete has been shown to induce amyloid fibrils in vitro, similar to human amyloid [26].

To test the hypothesis that bacteria might induce an amyloidogenic reaction in mammalian cells in vitro, we exposed cultures of rat primary neurons and astrocytes to the spirochete $B$. burgdorferi, and the PC 12 cell line to the 
bacterial inflammatory surface molecule lipopolysaccharide (LPS). We report here the results of such exposures.

\section{Methods}

Primary astrocyte and microglial cell cultures from Sprague-Dawley rats were prepared as previously described [14]. The astrocytes were cultured in Dulbecco's Modified Eagle Medium (DMEM, Gibco, 12387-015). The microglial cells were cultured in RPMI medium (RPMI 1640, Sigma R8758), containing 10\% fetal calf serum (FCS). Microgliaenriched astrocyte cultures $\left(10^{6}\right.$ astrocytes and $10^{5}$ microglia) were also prepared by combining astrocytic and microglia cultures prepared as described above. Neurons dissociated from the telencephalon of 21-day-old rats were cultured on collagen or poly-L-ornithine coated substrate surfaces [8]. The cells were cultured in 2-well chambers (177429 Lab-Tek, Christchurch, New Zealand), in 6-well clusters (3506, Costar, Acton, Maryland), and in $75 \mathrm{ml}$ of non-pyrogenic polystyrene flasks (3376, Costar, Acton, Maryland) in a humidified CO2 (6\%) incubator at $37^{\circ} \mathrm{C}$.

The organotypic culture consisted of aggregates of primary cells of foetal rat telencephalon that were kindly provided to us by Dr. P. Honegger [25]. These brain cell cultures were obtained at an advanced maturational stage (20-21 days in vitro). They were exposed to 2-4 weeks of continuous rotation at $37^{\circ} \mathrm{C}$, which produced a large number of small identical spheres containing a mixture of CNS cells, including neuronal and glial cells. These were infected with Borrelia spirochetes.

Reference spirochetes (B. burgdorferi, B31 strain) maintained in BSK II medium were used to infect the cell cultures. The cells were infected for periods of 2, 4, and 8 weeks. In cell cultures exposed to spirochetes, a mixture of equal volumes of medium from the given cell and spirochetes (BSK II) culture was used. The final concentration of spirochetes in the infected cultures corresponded to $5 \times 10^{5} / \mathrm{ml}$. Before exposure to spirochetes, the cells were tested with 4',6-diamidine-2'-phenylindole dihydrochloride (DAPI) (236 276, Boehringer Mannheim, Germany), following the manufacturer's protocol, in order to verify Mycoplasma infection. After 2-, 4-, and 8-week exposure, the cell cultures in double chambers and 6-well clusters were washed with PBS prior to immunohistochemical analysis. Cells in flasks were harvested by centrifugation in preparation for immunohistochemistry and Western blotting.

Exposure of cells to Borrelia spirochetes was done ten times with primary astrocyte cultures, four times with microglia-enriched astrocyte cultures, and three times with primary neurons and brain cell aggregates. The astrocyte and microglia-enriched astrocyte cultures were infected for periods of $1,2,4$, and 8 weeks, and the primary neuron and cell aggregate cultures for 1, 2, and 4 weeks. In addition, in each set of experiments, for all cell types and for each exposure time, the cells and cell aggregates were divided into six equal samples. Five of the samples were infected with spirochetes, while one uninfected sample was used as control. Immunohistochemical detection of $A \beta$ was done at each time point in each set of experiments for all cell types including cell aggregates.

Frozen sections, $5 \mu \mathrm{m}$ thick, were cut from the brain cell aggregates for immunohistochemistry. Cultures not infected with spirochetes were used as controls.

Smears prepared from the infected and uninfected cell cultures and frozen sections of the organotypic cultures were fixed in $4 \%$ paraformaldehyde and immunostained using the avidin-biotin-peroxidase technique. For immunostaining of cells or frozen sections on glass slides with anti-Borrelia antibodies, 15 min of acetone fixation was performed at $4{ }^{\circ} \mathrm{C}$. Those cultures in plastic chambers were fixed for $10 \mathrm{~min}$ with $4 \%$ paraformaldehyde. For A $\beta$ immunostaining, $100 \%$ formic acid pretreatment for 20 min was always used.

The antibody types, as well as their source, dilution and structures recognized are given in Table 1. Astrocytes were identified with anti-glial fibrillary acidic protein (GFAP); rat microglial cells with ED1 and human microglia with anti CD68. To detect $A \beta$, antibodies recognizing amino acids 8-17 of $A \beta$ and the C-terminal part of $A \beta$ 1-42 (21F12, a gift from Dr Dale Schenk, Athena Neurosciences) were used. To detect $A \beta P P$, the $22 \mathrm{C} 11$ antibody, which recognizes the $\mathrm{N}$ terminal part of all A $\beta P P$ isoforms was used. Tau protein was detected with T-6402, Tau 2, and clone AT8. The AT8 antibody recognizes phosphorylated Ser 202/Thr205 residues of tau, and labels PHF in AD. Borrelia antigens were detected with monoclonal anti-OspA and anti-flagellin antibodies, and also with rabbit anti-Borrelia antibodies. The anti-Borrelia antibodies were tested for their specificity to recognize Borrelia antigens by Western blotting using the BioGenex Lyme IgG Kit (D601-Lyme) following the instructions of the manufacturer.

For Western blots, whole cell extracts of infected and control primary astrocytes and microglia-enriched astrocytes were prepared in lysis buffer containing $1 \%$ protease inhibitors (P-8340, Sigma, St. Louis, MO). Triplicate samples from experiments at 2-, 4-, and 8-week exposure times were analyzed. They were continuously rotated for $4 \mathrm{~h}$ at $4{ }^{\circ} \mathrm{C}$ and were exposed to alternate boiling $\left(85^{\circ} \mathrm{C}\right)$ and cooling in dry ice, (three times, $1 \mathrm{~min}$ ). Extraction of $\mathrm{A} \beta$ was performed using formic acid as previously described in detail [9]. To $50 \mu \mathrm{g}$ protein samples, Laemmli buffer was added followed by boiling for $5 \mathrm{~min}$ at $85^{\circ} \mathrm{C}$. The samples were than electrophoresed on 14-20\% Tris-HCL and 4-20\% Tris-HCl-urea polyacrylamide gels (BioRad). Transfer onto a $0.2 \mathrm{~mm}$ nitrocellulose membrane (BioRad) was performed at $350 \mathrm{~mA}$ for $1.5 \mathrm{~h}$ at $4{ }^{\circ} \mathrm{C}$. Immunoblotting was performed using the antibodies mentioned above for the detection of $\mathrm{A} \beta, \mathrm{A} \beta \mathrm{PP}$, and tau proteins. For detection, ECL-Plus (Amersham, RPN2132) was used and the development of the film (Super RX, Fujifilm, 03G050) was performed in accordance with the manufacturer's protocol. Samples $(1 \mu \mathrm{g}$ or 500 ng) of synthetic A $\beta 1-42$ peptide (H 1368, Bachem, 
Table 1

The primary antibodies employed in the present study

\begin{tabular}{|c|c|c|c|c|}
\hline Antigen & Antibody [ref] & Source & Type & Dilution \\
\hline GFAP & Anti-GFAP Z334 & Dakopatts & Rabbit, IgG & $1: 1000$ \\
\hline ED1 & MCA341 & Dakopatts & Rabbit, IgG & $1: 1000$ \\
\hline CD68 & M 814 & Dakopatts & Mouse, IgG & $1: 2000$ \\
\hline$\beta$-Amyloid & M 872 & Dakopatts & Mouse, IgG & $1: 200$ \\
\hline $\mathrm{A} \beta \mathrm{1-42}$ & $21 \mathrm{~F} 12$ & Dr Dale Schenk & Mouse, IgG & $1: 100$ \\
\hline $\mathrm{A} \beta \mathrm{PP}$ & $22 \mathrm{C} 11,1285262$ & Boehringer & Mouse, IgG & $1: 100$ \\
\hline Tau & $\mathrm{T}-6402$ & Sigma & Rabbit, IgG & $1: 1000$ \\
\hline Tau 2 & $\mathrm{~T}-5530$ & Sigma & Mouse, ascites & $1: 20$ \\
\hline AT8 & AT8-PHF-Tau & Endothelin & Mouse, IgG & 1:1000 \\
\hline AT8 & BR-030 & Innogenetics & Mouse, IgG & $1: 1000$ \\
\hline OspA & H3T5 & Symbicom & Supernatant & 1:1000 \\
\hline OspA & H-5332 & Symbicom & Supernatant & $1: 1000$ \\
\hline Flagellin & H-9724 & Symbicom & Supernatant & $1: 100$ \\
\hline Flagellin & H-605 & Symbicom & Supernatant & $1: 100$ \\
\hline Borrelia burg & B65302R & Biodesign & Rabbit, IgG & $1: 200$ \\
\hline Borrelia burg & 1017 & J. Hurliman & Rabbit, IgG & $1: 500$ \\
\hline Borrelia burg & 1018 & J. Hurliman & Rabbit, IgG & $1: 500$ \\
\hline Grb2 & Clone 81 & BD Transd Lab & Mouse IgG & $1: 1000$ \\
\hline Actin, C-11 & sc-1615 & Santa Cruz & Goat IgG & $1: 2000$ \\
\hline
\end{tabular}

The source, type and the dilutions are given for each antibody.

Bubendorf, Switzerland) and $50 \mu \mathrm{g}$ samples of whole cell extracts prepared from pCMV/AßPP695 transfected U87MG cells were used as positive controls. Antibodies to actin and growth factor receptor bound protein 2 (Grb2) were used to verify loading conditions (see Table 1).

In order to analyze whether the bacterial component alone may induce changes in the A $\beta P P$ levels and in tau phosphorylation, bacterial lipopolysaccharide, an alternative powerful inflammatory stimulator was used to expose a mixture of PC12 cells and monocytic THP-1 cells. PC12 cells $\left(0.5 \times 10^{6}\right)$ were co-cultured with $0.1 \times 10^{6}$ THP- 1 cells in collagen coated Petri dishes $(100 \mathrm{~mm})$ for $24 \mathrm{~h}$ in $10 \mathrm{ml}$ of the following medium: $8 \mathrm{ml}$ of F12 Nutrient Mixture (HAM, 11765-054, Life Technologies, Gibco/BRL, Frederick, Maryland) and $2 \mathrm{ml}$ of VitaCell medium (ATCC, 30-2002, Manassas, Virginia). The medium was supplemented with $10 \%$ horse serum, 2,5\% FBS, $1 \%$ penicillin/streptomycin and $870 \mathrm{mg} \mathrm{NaHCO}_{3} / 500 \mathrm{ml}$ medium. LPS $(500 \mathrm{ng}$, S1K4072, Sigma, St. Louis, MO) was then added. After $0 \mathrm{~h}, 30 \mathrm{~min}, 3,24$, and $48 \mathrm{~h}$, the cells were harvested by centrifugation and whole cell extracts were analyzed by immunoblotting.

Densitometry analysis was performed using a Molecular Imager FX, equipped with Quantity one software (BioRad Laboratories, Hercules, CA).

In order to analyze whether the $\beta$-sheet conformation typical of amyloid is present in the Borrelia-induced amyloid deposits, Synchrotron InfraRed MicroSpectroscopy (SIRMS) analysis was performed. A Spectra Tech Continu $\mu \mathrm{m}$ infrared microscope coupled to a Nicolet Magna 860 FTIR was used, where the conventional infrared source was replaced by synchrotron light from Beamline U10B (National Synchrotron Light Source, Brookhaven National Laboratory). The infrared microscope was equipped with a light source and filters for fluorescence microscopy analysis [6,7]. For the SIRMS analysis, infected and uninfected cells were harvested by centrifugation, washed with PBS, placed on infrared-transparent $\mathrm{BaF}_{2}$ slides and stained with thioflavin S. Samples of infected and uninfected astrocyte cultures derived from three different experiments at 4-week exposure times were analyzed. Frozen sections from the frontal cortex of five AD and two control cases were also analyzed. Infrared microspectra were collected in transmission mode, 128 scans per point, $4 \mathrm{~cm}^{-1}$ resolution using Atl $\mu \mathrm{s}$ software (Thermo Electron Spectroscopy). The final data format was absorbance, where the background was collected open beam. Protein secondary structure was determined by Amide I infrared absorption band $\left(1600-1700 \mathrm{~cm}^{-1}\right)$ analysis. The frequency of Amide I band is sensitive to protein secondary structure, where $\beta$ sheet conformation absorbs near $1630 \mathrm{~cm}^{-1}$.

\section{Results}

We assessed whether $A \beta$ deposition could be induced in vitro by infecting primary mammalian neurons, astrocytes, microglial cells, and brain organotypic cell aggregates with spirochetes. We used B. burgdorferi spirochetes, as they can be maintained in culture in synthetic medium (BSKII). The histochemical and immunohistochemical analysis showed the same results, with respect to the $A \beta$ deposition, in the form of plaque-like structures in all cell types and in the cell aggregates exposed to Borrelia.

Following 1-week exposure to spirochetes, $A \beta$ was not detected in any infected cells or cell aggregate samples. At 2-week exposure to Borrelia, immunohistochemical detection of $A \beta$ was observed in $4 / 10$ of the astrocyte cultures, in $3 / 4$ of the microglia-enriched astrocytic cultures and in 
$2 / 3$ of the neuronal cultures and in cell aggregates. $A \beta$ deposition was observed in all cells and cell aggregates following 4 and 8 weeks of exposure to spirochetes. Plaquelike $A \beta$ deposits following 4-week exposure to spirochetes as revealed by immunostaining is illustrated in Fig. 1a-e. They were in a consolidated form as revealed by thioflavin $\mathrm{S}$ staining (Fig. 1c and d). The majority of the amyloid deposits were large $(100-150 \mu \mathrm{m})$ extracellular aggregates (Fig. 1a-e). Their numbers varied between 5 and 20 per well and between 2 and 10 per spheroid in the cell aggregates. A weak intracellular $A \beta$ immunoreactivity was also apparent in some cells in brain aggregates infected with Borrelia for 2-4 weeks (Fig. 1a, arrows). The in vitro induced "plaques" were immunoreactives with the $6 \mathrm{~F} / 3 \mathrm{D}$ antibody recognizing residues $8-17$ of $A \beta$ (Fig. 1a, $b$ and e) and also with the anti-A $\beta$ 1-42 (21F12) antibody (Fig. 1g).

In the infected neuronal and organotypic cultures, a few $A \beta-42$ and OspA-positive tangle-like formations were also observed (Fig. 1g-i, respectively). OspA-positive intracytoplasmic granules in astrocytes, surrounded by a thin pale halo, similar to granulovacuolar degeneration of neurons in AD, were also seen (Fig. 1j). Only rare, OspA-positive solitary intracytoplasmic granules were seen in a few neurons in the infected neuronal cultures. The uninfected control cultures did not show $\mathrm{A} \beta$ deposition, or granulovacuolar degeneration (Fig. 1k).

We detected a $4 \mathrm{kDa} \mathrm{A} \beta$ peptide band by Western blot (Fig. 2a and b), in all cell culture samples analyzed, following 2-8 weeks of exposure to Borrelia spirochetes. The presence of the $31 \mathrm{kDa}$ outer surface protein (OspA) of B. burgdorferi was utilized to monitor the presence of spirochetal infection. After 2-week exposure to Borrelia spirochetes, the A $\beta$ deposition was absent or weak in primary rat astrocytes (Fig. 2a) but was more pronounced in microglia-enriched astrocyte cultures (Fig. 2b), suggesting that microglia enhance $A \beta$ formation. Cell cultures infected for 8 weeks showed a higher level of $A \beta$ than those infected for 2 weeks (Fig. 2b). $A \beta$ was not observed in the uninfected control cultures (Fig. 1a and $\mathrm{b}$ ).

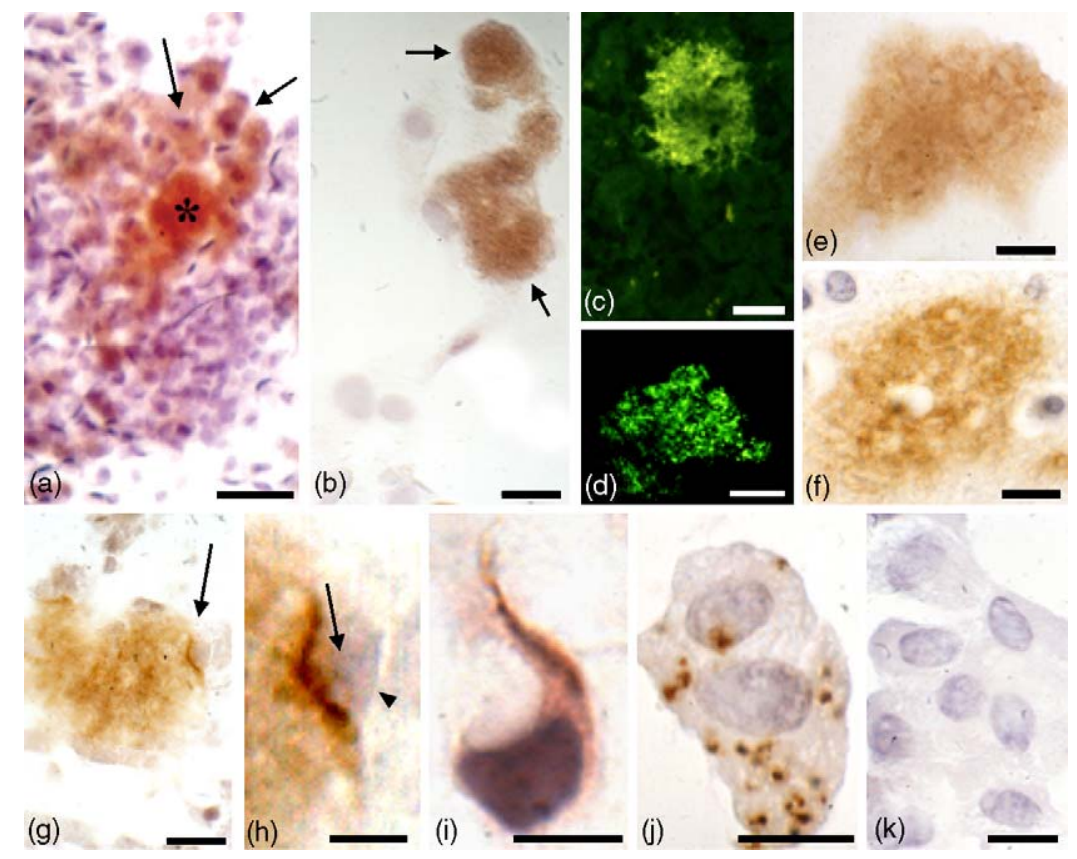

Fig. 1. In vitro $A \beta$ deposition induced by exposure to Borrelia burgdorferi for 4 weeks. A $\beta$ immunoreactive and thioflavin S-positive plaque-like formations illustrated in brain cell aggregates (a), in primary rat astrocytic culture (b, c and e) and in neuronal culture (d). For immunostaining, a monoclonal antibody, which recognizes residues 8-17 of $\mathrm{A} \beta$ was used, and the sections were counterstained with hematoxylin. (a) Frozen section of a spheroid from infected brain cell aggregates. The section represents half portion of a spheroid of aggregated brain cells. A large extracellular deposit labeled with an asterisk. Arrows point to apparently intracellular deposits showing weak $A \beta$ reactivity in some unidentified cells. (b) Arrows point to large plaque-like extracellular deposits. (c and d) Thioflavin S-positive "plaques in astrocytic (c) and neuronal (d) culture. (e and f) A $\beta$-immunoreactive "plaque" induced in vitro (e) and A $\beta$-immunoreactive senile plaques in the cerebral cortex of a sporadic $\mathrm{AD}$ case (f), where a paraffin section from the frontal cortex was immunostained using the same anti- $\mathrm{A} \beta$ antibody as used for (e). Notice the similarity in morphology and $A \beta$-immunoreactivity of the in vitro induced deposits and that of the senile plaque (i.e. compare (e with f)). (g) At the periphery of a A $\beta$-immunoreactive "plaque", a structure reminiscent of a neurofibrillary tangle (arrow) in the organotypic culture exposed to B. burgdorferi. (h) At higher magnification, the large nucleus (arrowhead) and nucleolus (arrow) of the cell indicates that the cell morphologically corresponds to a neuron. A frozen section was cut from cell aggregates following 2-week exposure to $B$. burgdorferi and immunostained with anti-A $\beta 1-42$ (21F12) antibody followed by counterstaining with hematoxylin. (i) Neuron showing morphological changes reminiscent of neurofibrillary tangle formation. A rat primary neuronal culture was exposed to spirochetes for 2 weeks. Immunostaining was performed with an antibody, which recognizes the outer surface protein A (OspA) of B. burgdorferi. The section was counterstained with hematoxylin. (j) OspA immunoreactive intracytoplasmic granules (arrows), surrounded with a pale halo, reminiscent to the morphology of granulovacuolar degeneration. A primary rat astrocyte culture was infected with Borrelia spirochetes. In control cultures (k), not exposed to spirochetes (primary rat astrocyte culture), these morphological changes were not observed. Bars: $120 \mu \mathrm{m}$ (a); $50 \mu \mathrm{m}$ (b-d and $\mathrm{g}) ; 20 \mu \mathrm{m}(\mathrm{e}-\mathrm{k})$. 

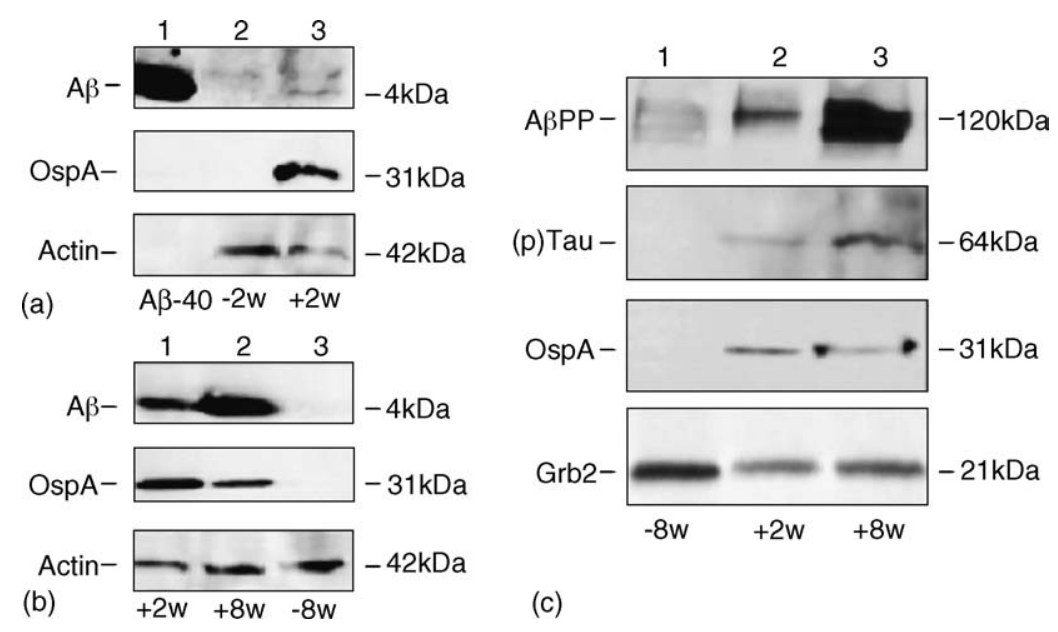

(c)

Fig. 2. Western blot analysis of $\mathrm{A} \beta, \mathrm{A} \beta \mathrm{PP}$ and tau following exposure to Borrelia burgdorferi and LPS. The number of weeks after bacterial infection was entered "(+) number of weeks (w)", and the number of weeks of the uninfected control maintained in parallel in culture "( - ) number of weeks (w)". (a) Lane 1, synthetic "A $\beta-40$ "; lane 2, control primary astrocye culture maintained for 2 weeks $(-2 \mathrm{w})$; lane 3 , infected primary astrocytic culture exposed to Borrelia for 2 weeks (lane $3,+2 \mathrm{w}$ ). In (a), a very weak $4 \mathrm{kDa} A \beta$ reactive band is seen in primary rat astrocytes exposed to Borrelia spirochetes for 2 weeks (a, $+2 \mathrm{w}$ ), which is absent in the control culture. OspA is absent in the uninfected and present in the infected culture. Lane 1 shows that the purified A $\beta-40$ does not react with OspA and actin antibodies. (b) Lane 1, microglia-enriched culture infected for 2 weeks $(+2 \mathrm{w})$; lane 2, infected for 8 weeks $(+8$ w); lane 3 , uninfected culture maintained uninfected for 8 weeks $(-8 \mathrm{w})$. In $(\mathrm{b})$, a stronger band was observed in microglia-enriched cultures exposed to bacteria (b, $+2 \mathrm{w})$. Following 8 -week exposure to spirochetes $(\mathrm{b},+8 \mathrm{w})$, the $\mathrm{A} \beta$ level was much higher than at 2 weeks $(\mathrm{b},+2 \mathrm{w})$. The $4 \mathrm{kDa} A \beta$ band was reactive with antibodies recognizing amino acids 7-15 of $A \beta$ or the C-terminal part of $A \beta 1-42$. An antibody to the $31 \mathrm{kDa}$ outer surface protein (OspA) of B. burgdorferi was utilized to monitor the presence of spirochetal infection, and an antibody to the $42 \mathrm{kDa}$ protein actin was used to verify loading conditions. In uninfected cells cultured for 2 (a, $-2 \mathrm{w}$ ) and 8 weeks (b, $-8 \mathrm{w}) \mathrm{A} \beta$ was not detected. (c) A $\beta$ PP expression: lane 1, uninfected primary rat astrocytes maintained for 8 weeks $(-8 \mathrm{w})$; lane 2 , primary rat astrocytes exposed to Borrelia for 2 weeks $(+2 \mathrm{w})$ and lane 3 , for 8 weeks $(+8 \mathrm{w})$. Compared to the uninfected control culture (c, $-8 \mathrm{w})$, primary rat astrocytes exposed to Borrelia spirochetes for $2(\mathrm{c},+2 \mathrm{w})$ and $8(\mathrm{c},+8 \mathrm{w})$ weeks showed increased A $\beta P P$ levels and hyperphosphorylation of tau. For immunoblotting, antibody 22C11, which recognizes the N-terminal part of all A $\beta P P$ isoforms, and AT8, which recognizes the phosphorylated Ser 202/Thr205 epitope of tau, were used. The A $\beta P P$ and $(p)$ tau levels were higher at 8 weeks than at 2-week exposure. The $31 \mathrm{kDa}$ Borrelia OspA was used to monitor infection and the growth factor receptor-bound protein 2 (Grb2) to verify loading conditions.

To determine whether $\mathrm{A} \beta \mathrm{PP}$ plays a role in $\mathrm{A} \beta$ deposition induced by Borrelia spirochetes in vitro, we analyzed $A \beta P P$ levels in infected cell cultures using Western blot analysis. In comparison to the uninfected control cultures, increased A $\beta$ PP levels were detected in Borrelia-infected cultures (Fig. 2c). AßPP levels were higher at 8 weeks than at 2 weeks following exposure to spirochetes.

The microtubule-associated protein tau is hyperphosphorylated in $\mathrm{AD}$ and is a component of paired helical filaments (PHF) in neurofibrillary tangles. When we analyzed the phosphorylation of tau in cell cultures exposed to Borrelia spirochetes, increased phosphorylated tau levels were observed when compared to the uninfected control cultures (Fig. 2c).

Natural or synthetic bacterial components alone may lead to chronic inflammation and amyloid deposition [10,11]. We analyzed, therefore, whether the bacterial lipopolysaccharide could alone induce increased A $\beta P$ and hyperphosphorylation of tau. As microglia enhanced $A \beta$ formation in primary cell cultures, PC12 cells were co-cultured with THP-1 cells before treatment with LPS. By immunoblotting, a slight increase of $\mathrm{A} \beta P P$ was detected following $30 \mathrm{~min}$ and $6 \mathrm{~h}$ LPS exposure, followed by a strong increase at 24 and $48 \mathrm{~h}$ (Fig. 3). In addition, we also observed hyperphosphorylation of tau following 24 and $48 \mathrm{~h}$ LPS exposure (Fig. 3).
The infrared absorption microspectrum of healthy brain tissue exhibits a protein (Amide I) absorbance maximum near $1655 \mathrm{~cm}^{-1}$, representative of an average $\alpha$-helical protein structure in the tissue [6]. SIMRS analysis detected a second peak near $1630 \mathrm{~cm}^{-1}$ in senile plaques in $\mathrm{AD}$, representative of $\beta$-sheet protein structure. Most importantly, a second peak near $1630 \mathrm{~cm}^{-1}$ was also observed in the thioflavin S-positive "plaques" in the cell cultures analyzed following 4-week exposure to spirochetes (Fig. 4a, b, d), which was absent in the uninfected control samples (Fig. 3c and e).

\section{Discussion}

Exposure of mammalian neuronal and glial cells to Borrelia spirochetes induced the defining pathological hallmarks of $\mathrm{AD}$, including $\mathrm{A} \beta$ deposition, increased $\mathrm{A} \beta \mathrm{PP}$ levels, and hyperphosphorylation of tau.

Thioflavin S-positive and A $\beta$-immunoreactive "plaques", as well as tangle- and granulovacuolar-like formations, were present in cell cultures exposed to Borellia burgdorferi spirochetes. In addition, Western blot analysis detected a $4 \mathrm{kDa}$ $\mathrm{A} \beta$ immunoreactive band in the infected cultures.

SIMRS is an extremely valuable tool for the analysis of chemical composition of biological and biomedical samples [7]. The chemical spectra of protein solutions, single cells or 

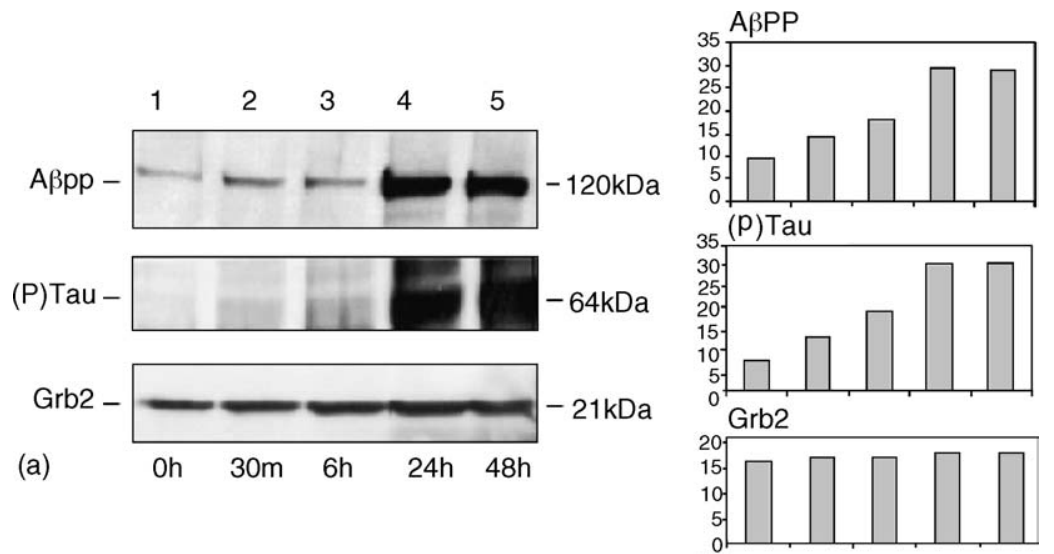

(b) $0 \mathrm{~h} 30 \mathrm{~m} \quad 6 \mathrm{~h} \quad 24 \mathrm{~h} \quad 48 \mathrm{~h}$

Fig. 3. LPS-induced changes of A $\beta P P$ and tau. (a) Lanes 1-5, PC12/THP-1 cells exposed to LPS for $0 \mathrm{~h}, 30 \mathrm{~min}, 6,24$, and $48 \mathrm{~h}$. Increased A $\beta P P$ and $(p)$ tau levels were observed in PC12/THP-1 cells following 24 and $48 \mathrm{~h}$ of LPS (500 ng) exposure. Densitometry analysis (b) clearly showed the increased A $\beta$ PP expression and $(p)$ tau levels when compared to the growth factor receptor-bound protein 2 (Grb2), used to verify loading conditions. Each bar represents the mean density from three different gels.

well-defined areas of tissue sections can be analyzed. Characteristic absorption bands observed in many biological materials include the 'Amide I' band at $1650 \mathrm{~cm}^{-1}$ resulting largely from the number of carbonyl $(\mathrm{C}=\mathrm{O})$ stretching vibrations of protein amide bonds. A second peak in the "Amide I" band near $1630 \mathrm{~cm}^{-1}$, is present in senile plaques representative of $\beta$-sheet protein structure [6]. This peak near $1630 \mathrm{~cm}^{-1}$ was observed not only in the senile plaques of the $5 \mathrm{AD}$ cases tested, but also in the thioflavin S-positive "plaques" in infected cell cultures following 4-week exposure to Borrelia.

These observations indicate that exposure of mammalian cells to Borrelia spirochetes induces an AD-like host cell reaction. Recent observations show that several bacteria
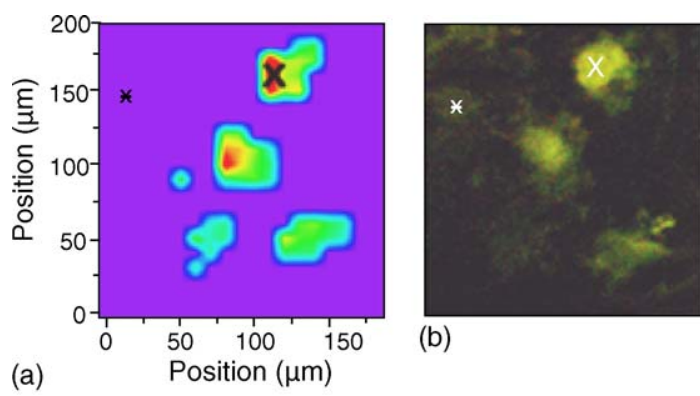

(b)

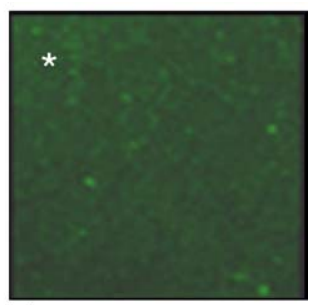

(c)
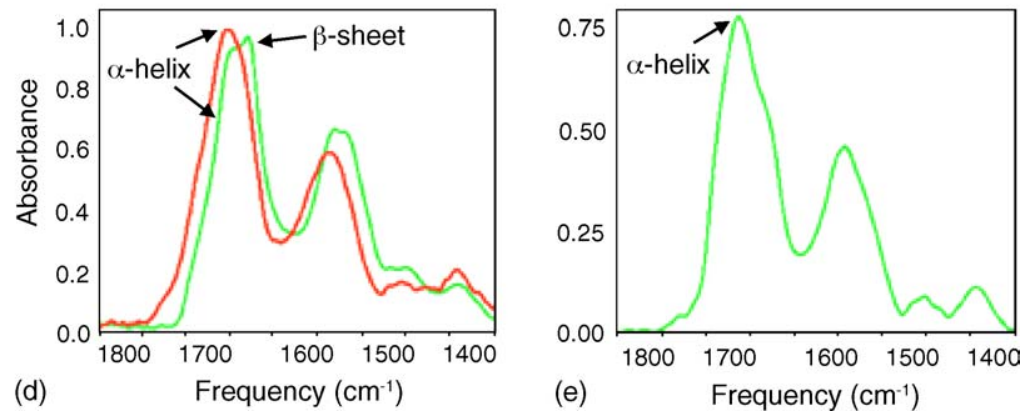

Fig. 4. Synchrotron infrared microspectroscopy analysis of the in vitro induced $A \beta$ deposition in cell cultures exposed to Borrelia spirochetes for 4 weeks. (a) Chemical map based on infrared microspectroscopy data showing the relative concentration of $\beta$-sheets in the Borrelia-infected culture. Red corresponds to an increased concentration and purple to normal levels. The areas of increased $\beta$-sheet formation of the chemical map correspond to the thioflavin S-positive plaque-like formations induced in vitro (compare (b with c)). (d) The green infrared Amid spectrum taken from the center of the thioflavins S-positive amyloid "plaque" labeled with $X$ in ( $a$ and $b$ ), showed a peak near $1630 \mathrm{~cm}^{-1}$, which is indicative of $\beta$-sheet. The red spectrum in (d), was taken from a thioflavin $\mathrm{S}$-negative area of the same infected culture (marked with an asterisk in (a and b)) showed a peak near $1650 \mathrm{~cm}^{-1}$, which is consistent with $\alpha$-sheet formation. (c) In thioflavin S-stained control cultures (c), not exposed to spirochetes, plaque-like formation was not observed and the Amid spectrum corresponded to $\alpha$-sheet formation. (e) Shows the amid spectrum of the area labeled with an asterisk in (c). 
contain amyloidogenic proteins $[5,15,19,21-23,26]$. Analysis of the periplasmic outer membrane lipoprotein - OsmB - of Escherichia coli showed a similarity in amino acid sequences to $A \beta$ peptide [15]. Recent biochemical, biophysical, and imaging analyses revealed that fibers produced by E. coli, termed "curly" were composed of amyloid [5]. It was suggested that several types of spirochetes may be involved in $\mathrm{AD}$, and also that amyloidogenic proteins may be an integral part of spirochetes, which may, therefore, play a role in amyloidogenesis in AD [18-25,31]. Furthermore, it was shown that the OspA outer surface protein of B. burgdorferi forms amyloid fibrils in vitro, similar to human amyloid [26]. These observations are in line with the present findings showing that $A \beta$ formation may be induced in vitro following exposure of mammalian cells to B. burgdorferi. Recently, the formation of amyloid deposits resembling $\mathrm{AD}$ plaques was induced in the brains of mice following intranasal infection with another bacterium, Chlamydia pneumoniae [17].

In addition to the bacteria-induced $A \beta$ "plaques" tanglelike structure were also immunoreactives with an anti-A $\beta$ antibody (21F12), which recognizes $A \beta-42$. There are evidences that $A \beta P P$ and $A \beta$ immunoreactivities are both associated with neurofibrillary tangles $[28,33]$.

Bacteria-induced $A \beta$-positive plaque- and tangle-like structures were also immunoreactive to Borrelia antigens. One might hypothesize that the anti-OspA "plaque" and "tangle" formed first, and then had $A \beta$ deposited on them. This would also suggest that thread-like helically shaped microorganisms would be important for the formation of bacteria-induced tangle-like structures. This hypothesis would be in harmony with recent observations that in $\mathrm{AD}$ cases with a positive serology for Lyme disease, spirochetal antigens were co-localized with $A \beta$ and were present not only in senile plaques but also in neurofibrillary tangles [24]. Detailed immunohistochemical and electron microscopical analysis of the Borrelia-induced "plaques" and "tangles" would be important. However, the restricted number of "tangle" formations and the short time that we are able to maintain cells in cultures are not optimal for such studies. In vivo studies, with a longer exposure time would be necessary to study efficiently the sequence of events and the cellular mechanisms involved in the bacteria-induced beta-amyloid deposition and "tangle" formation. Similarly, it is difficult to determine from the present in vitro studies, whether $A \beta$ deposits are initially intracellular then became extracellular, or whether they are from the beginning extracellular. To answer this question, further in vitro and in vivo studies will be necessary.

The occurrence of intracytoplasmic granular changes in astrocytes and microglia in $\mathrm{AD}$ was previously reported [29]. A recent report showed the presence of granular structures recognized by the C-terminal part, but not the $\mathrm{N}$-terminal part of the $\mathrm{A} \beta$ peptide in a subset of astrocytes and microglia [1]. To answer whether the bacteria-induced OspA-positive intracytoplasmic granules in astrocytes may be related to these glial changes and whether they may represent changes similar to neuronal granulovacuolar degeneration will require further in vitro and in vivo studies.

The increased A $\beta P P$ level observed in cell cultures following exposure to Borrelia spirochetes or LPS reinforces the importance of host-derived $\mathrm{A} \beta \mathrm{PP}$ in amyloidogenesis. A $\beta \mathrm{PP}$ is a proteoglycan core protein [32,35]. It is well established that increased proteoglycan synthesis plays a significant role in amyloidogenesis, including the formation of $A \beta$ in $A D$ [4]. Proteoglycans are present in early stages of amyloid deposition, but their exact role is yet to be determined. An important role for proteoglycans in major histocompatibility complex (MHC)-mediated infections (e.g. viral, bacterial) is also well documented. The in vivo synthesis of proteoglycans by host cells in response to bacterial infections, including spirochetal infections [34], has been previously reported.

The microtubule-associated protein tau is hyperphosphorylated in $\mathrm{AD}$ and is a component of the paired helical filaments of neurofibrillary tangles. When we analyzed the phosphorylation of tau in cell cultures exposed to Borrelia spirochetes, increased phosphorylated tau levels were observed. Although further analysis will be required to identify in detail the specific tau phosphorylation sites, the Borrelia- and LPS-induced tau phosphorylation represents additional experimental evidence of the ability of bacteria to induce an AD-like host cell reaction.

Natural or synthetic bacterial components, such as the bacterial cell wall peptidoglycan and LPS may induce chronic inflammation and amyloidosis [10,11]. They are inflammatory cytokine stimulators, they activate complement, they affect vascular permeability, they generate nitric oxide, and they induce proteoglycan synthesis and apoptosis [10-13]. All of these processes are implicated in the pathogenesis of AD.

We observed increased $\mathrm{A} \beta \mathrm{PP}$ and hyperphosphorylation of tau not only in cell cultures exposed to Borrelia spirochetes but also in PC12/THP-I cell cultures exposed to LPS. These findings indicate that increased A $\beta P P$ together with hyperphosphorylation of tau may be induced not only by living bacteria, but also by biologically active bacterial components alone. In agreement with the present observations, increased A $\beta P P$ mRNA was also reported to occur in the basal forebrain region and the hippocampus in the rat in response to LPS. In addition, $A \beta$ deposition was observed in the brains of rats chronically infused with lipopolysaccharide $[12,13]$.

Mammals are constantly exposed to bacteria. Bacterial cell components are highly resistant to degradation by mammalian enzymes, and thus may provide persisting inflammatory and amyloidogenic stimuli [10]. During chronic exposure, bacteria or bacterial debris may accumulate and persist in host tissues and trigger a cascade of events leading to chronic inflammation and amyloid deposition. 
In conclusion, the present results reinforce previous observations that spirochetes can induce a host reaction with similarities to that seen in AD. The results indicate that bacteria and/or their degradation products may enhance a cascade of events leading to amyloid deposition in $\mathrm{AD}$.

\section{Acknowledgements}

We would like to express our thanks to all those scientists, colleagues, patients and friends who encouraged and strongly supported this work in so many different ways. We are very grateful to P.L. McGeer, J.L. Farber and A.M. Stunckard for the important helpful and critical review of the manuscript, and for the precious help of J. Krasinski and M. Maurin. Without their support and help, this work could not have been completed. This research was supported by a grant from the Societe Academique Vaudoise and by the University Institute of Histology and Embryology, University of Neuchatel, Switzerland. The National Synchrotron Light Source is supported by the U.S. Department of Energy under Contract No. DE-AC02-98CH10886.

\section{References}

[1] Akiyama H, Schwab C, Kondo H, Mori H, Kametani F, Ikeda K, et al. Granules in glial cells of patients with Alzheimer's disease are immunopositive for C-terminal sequences of beta-amyloid protein. Neurosci Lett 1996;206:169-72.

[2] Alzheimer A. Über Eigenartige Krankheitsfälle des späteren Alters. Zeitschr f d Ges Neurol Psychiatr 1911;4:356-85.

[3] Bonfiglio F. Di speciali reperti in un caso di probabile sifilide cerebrale. Concerning special findings in a case of probable cerebral syphilis. Riv Sperim Fren 1908;34:42-72.

[4] Castillo GM, Cummings JA, Ngo C, Yang W, Snow AD. Novel purification and detailed characterization of perlecan isolated from the Engelbreth-Holm-Swarm tumor for use in an animal model of fibrillar A beta-amyloid persistence in brain. J Biochem 1996;120: 433-44.

[5] Chapman MR, Robinson LS, Pinkner JS, Roth R, Heuser J, Hammar M, et al. Role of Escherichia coli curli operons in directing amyloid fiber formation. Science 2002;295:851-5.

[6] Choo LP, Wetzel DL, Halliday WC, Jackson M, LeVine SM, Mantsch HH. In situ characterization of beta-amyloid in Alzheimer's diseased tissue by synchrotron Fourier transform infrared microspectroscopy. Biophys J 1996;71:1672-9.

[7] Dumas P, Jamin N, Teillaud JL, Miller LM, Beccard B. Imaging capabilities of synchrotron infrared microspectroscopy. Faraday Discuss 2004;126:289-302.

[8] Fiumelli H, Kiraly M, Ambrus A, Magistretti P, Martin JL. Opposite regulation of calbindin and calretinin expression by brainderived neurotrophic factor in cortical neurons. J Neurochem 2000;74:1870-7.

[9] Fonte J, Miklossy J, Atwood C, Martins RN. The severity of cortical Alzheimer's type changes is positively correlated with increased amyloid- $\beta$ levels: resolubilization of amyloid- $\beta$ with transition metal ion chelators. J Alzheimer's Dis 2001;3:209-19.

[10] Fox A. Role of bacterial debris in inflammatory diseases of the joint and eye. APMIS 1990;98:957-68.

[11] Foyn Bruun C, Rygg M, Nordstoga K, Sletten K, Marhaug G. Serum amyloid A protein in mink during endotoxin induced inflammation and amyloidogenesis. Scand J Immunol 1994;40:337-44.

[12] Hauss-Wegrzyniak B, Vraniak PD, Wenk GL. LPS-induced neuroinflammatory effects do not recover with time. Neuroreport 2000;11:1759-63.

[13] Hauss-Wegrzyniak B, Wenk GL. Beta-amyloid deposition in the brains of rats chronically infused with thiorphan or lipopolysaccharide: the role of ascorbic acid in the vehicle. Neurosci Lett 2002;322:75-8.

[14] Janzer RC, Raff MC. Astrocytes induce blood-brain barrier properties in endothelial cells. Nature 1987;325:253-7.

[15] Jarrett JT, Lansbury PT. Amyloid fibril formation requires a chemically discriminating nucleation event: studies of an amyloidogenic sequence from the bacterial protein OsmB. Biochemistry 1992;31:12345-52.

[16] Kang J, Lemaire HG, Unterbeck A, Salbaum JM, Masters CL, Grzeschik KH, et al. The precursor of Alzheimer's disease amyloid A4 protein resembles a cell-surface receptor. Nature 1987;325: 733-6.

[17] Little CS, Hammond CJ, MacIntyre A, Balin BJ, Appelt DM. Chlamydia pneumoniae induces Alzheimer-like amyloid plaques in brains of BALB/c mice. Neurobiol Aging 2004;25:41929.

[18] MacDonald AB. Concurrent neocortical borreliosis and Alzheimer's disease. Ann N Y Acad Sci 1988;539:468-70.

[19] Miklossy J. Alzheimer's disease-a spirochetosis? Neuroreport 1993;4:841-8.

[20] Miklossy J, Kasas S, Celio M, Janzer RC, Ardizzoni F, Van der Loos H. Further morphological evidence for a spirochetal etiology of Alzheimer's disease. Neuroreport 1994;5:1201-4.

[21] Miklossy J. The spirochetal etiology of Alzheimer's disease: a putative therapeutic approach. Alzheimer disease: therapeutic strategies. In: Giacobini E, Becker R, editors. Proceedings of the third international Springfield Alzheimer symposium, Part I. Birkhauser Boston Inc.; 1994. pp. 41-48.

[22] Miklossy J, Darekar P, Gern L, Janzer RC, Bosman FT. Bacterial peptidoglycan in neuritic plaques in Alzheimer's disease. Azheimer's Res 1996;2:95-100.

[23] Miklossy J. Chronic inflammation and amyloidogenesis in Alzheimer's disease: putative role of bacterial peptidoglycan, a potent inflammatory and amyloidogenic factor. Alzheimer's Rev 1998;3:45-51.

[24] Miklossy J, Khalili K, Gern L, Ericson RL, Darekar P, Bolle L, et al. Borrelia burgdorferi persists in the brain in chronic lyme neuroborreliosis and may be associated with Alzheimer disease. J Alzheimer's Dis $2004 ; 6: 1-11$.

[25] Monnet-Tschudi F, Zurich MG, Honegger P. Comparison of the developmental effects of two mercury compounds on glial cells and neurons in aggregate cultures of rat telencephalon. Brain Res 1996;741:52-9.

[26] Ohnishi S, Koide A, Koide SJ. Solution conformation and amyloidlike fibril formation of a polar peptide derived from a $\beta$ hairpin in the OspA single-layer $\beta$-sheet. Mol Biol 2000;301:47789.

[27] Pacheco e Silva AC. Localisation du Treponema pallidum dans le cerveau des paralytiques généraux. Rev Neurol 1926;2:55865.

[28] Perry G, Richey PL, Siedlak SL, Smith MA, Mulvihill P, DeWitt DA, et al. Immunocytochemical evidence that the beta-protein precursor is an integral component of neurofibrillary tangles of Alzheimer's disease. Am J Pathol 1993;143:1586-93.

[29] Perusini G. Ueber klinisch und histologisch eigenartrige psychische Erkrankungen des spaeteren Lebensalters. In: Nissl F, Alzheimer A, editors. Histologische and histopathologische Arbeiten, vol. III. Jena: Gustav Fischer; 1910. p. 297-351.

[30] Picken MM. The changing concepts of amyloid. Arch Pathol Lab Med 2001;125:38-43. 
[31] Riviere GR, Riviere KH, Smith KS. Molecular and immunological evidence of oral Treponema in the human brain and their association with Alzheimer's disease. Microbiol Immunol 2002;17: 113-8.

[32] Schubert D, Schroeder R, LaCorbiere M, Saitoh T, Cole G. Amyloid beta protein precursor is possibly a heparan sulfate proteoglycan core protein. Science 1988;241:1759-63.

[33] Schwab C, McGeer PL. Abeta42-carboxy-terminal-like immunoreactivity is associated with intracellular neurofibrillary tangles and pick bodies. Exp Neurol 2000;161:527-34.
[34] Strugnell RA, Kent T, Handley CJ, Faine S. Experimental syphilitic orchitis: relationship between Treponema pallidum infection and testis synthesis of proteoglycans. Am J Pathol 1988;133: $110-7$.

[35] Wu A, Pangalos MN, Efthimiopoulos S, Shioi J, Robakis NK. Appican expression induces morphological changes in C6 glioma cells and promotes adhesion of neural cells to the extracellular matrix. $\mathbf{J}$ Neurosci 1997;17:4987-93. 